\title{
THIRD PARTY AGGRESSION: EFFECTS OF COOPERATION AND SIMILARITY TO INGROUP MEMBER
}

\author{
Tomohiro KUMAGAI and Ken-ichi OHBUCHI
}

Tohoku University, Japan

\begin{abstract}
The purpose of the present study was to examine the effect of similarity of group member and cooperative experience on aggression by the third party person who was not personally suffered. 96 participants were assigned into one of four conditions; 2 (high similarity or low similarity) $\times 2$ (cooperative experience or noncooperative experience). In every condition, the participants observed the victim and then, they were given a chance to retaliate against the harm-doer. The result showed that the cooperative experience increased aggressive behavior. And the perception of threat and aggressive intent mediated between them. Further, the cooperative experience directly increased the aggressive intent and the similarity prompted the aggressive response. We discussed these results from a social identity perspective.
\end{abstract}

Key words: third party aggression, group identification, cooperative experience

From international warfare to interpersonal conflicts, we frequently see cases in which a third party intervenes into the events. One type of third party intervention is that which is requested by participants, such as divorce meditation in family court, and another type is the spontaneous intervention by a third party, as in settling a quarrel. Third party intervention may succeed in setting conflicts if it appeases the participants or makes offer to fit their interests. In contrast, it may escalate the conflicts if a third party takes a sided position in for of one and against the others.

Huntington (1996) pointed out that domestic and international conflicts are sometimes escalated by third party intervention; One such example is when a third party group decides to intervene in a group conflict, not for economic reasons such as social class or disparity in wealth, but for the purpose of supporting people who belong to the same group. Further, in actions of the United Nations, we can find cases in which third party intervention based on goodwill caused serious problems. The United Nations has intervened to end civil wars and to save refugees, but its action sometimes has increased conflicts and the number of refugees (e.g., Ignatieff, 1998). As such, case studies have found that spontaneous intervention sometimes escalates conflicts. These studies have given explanations for it, but this phenomenon has not been observed in laboratory

This study was supported by the Center for the Study of Social Stratification and Inequality at Tohoku University under the 21 st Century COE Program.

The authors wish to thank Mie Endo. She helped to conduct the experiment.

Correspondence concerning this article should be addressed to Kumagai Tomohiro, The 21st Century Center of Excellence Program, Tohoku University, Center for the Study of Social Stratification and Inequality. Kawauchi 27-1, Aoba ward, Sendai, 980-8576, Japan (e-mail: kumagai@sal.tohoku.ac.jp.) 
settings. This type of conflict escalation occurs both in international as well as interpersonal levels, and it causes serious damage to social relationships at each level. Therefore, it is crucial to investigate the psychological mechanism of conflict escalation by third party intervention. In the present study, we observed that third party person receiving no harm intervened into other's conflict with aggressive ways in a laboratory setting. Consequently, we attempted to examine psychological and social processes of aggressive behavior in that situation.

A potent motive for aggressive response to harm is retaliation (Baron \& Richardson, 1994; Tedeschi \& Felson, 1994). Retaliation is the act of causing a harm-doer the same amount of physical or psychological harm as one has suffered. It has been regarded as an attempt to restore fairness that was impaired by unjust harm or to prevent further harm (Ohbuchi, 1996; Dengerink \& Covey, 1983). Sometimes in harm situations, however, persons other than the victims are motivated to retaliate. After the September 11th terrorist attacks, American people supported U.S. military action against Afghanistan, even though most of them did not personally suffer from the tragedy. So, what caused their strong retaliatory motivation? We supposed that the sense of shared group membership with the victims motivates, the third party persons retaliate the harm-doer. In a study of inter-group emotions, Mackie, Devos, and Smith (2000) showed when social identity was salient, a group-based appraisal elicits strong emotions even if such an appraisal done was made not for personal matter. Thus, it was predicted that when an individual identifies himself/herself with a group, he/she would perceive a harm inflicted to another ingroup member as a negative evaluation for the group, emotionally react to it, and retaliate the harm-doer.

Group identification is defined as the assimilation of the self into ingroup prototype. What factors do enhance group identification? Jackson and Smith (1999) found four factors of group identification: Perception of the intergroup context such as antagonism or competition (Ellemers, Doosje, Van Knippenberg, \& Wilke, 1992; Ellemers, Van Rijswijk, Roefs, \& Simons, 1997), attraction to the ingroup such as similarity to group members or fair treatment (Brewer \& Pickett, 1999; Brewer \& Kramer, 1986; Tyler, Degoey, \& Smith, 1996), interdependency belief and perceived common fate (Rabbie \& Horwitz, 1969; Rosenbaum, Moore, Cotton, Cook, Hieser, Shover, \& Gray, 1980), and depersonalization (Postmes, Spears, Sakhel, \& de Groot, 2001). In this study, we focused on attraction to ingroup and interdependency.

A well known factor of attraction to ingroup is intragroup similarity (Brewer \& Kramer, 1986). Similarity with other ingroup members is recognized as a signal of correctedness of personal attitude or behavior. Thus, similarity may enhance identification with the group. Based on the above discussion, we made a prediction: When participants observed that the other ingroup member was harmed, they would be more likely to feel stronger hostility and more aggressively respond to the harm-doer if they perceived similarity between them and the ingroup member than if they did not perceive it (Hypothesis 1).

Another factor of group identification is interdependency between ingroup members. Rosenbaum, et al., (1980) showed that participants more positively evaluated their group 
when they were rewarded according to the cooperative total outcomes than when they were rewarded according to their personal contributions. It is interpreted that interdependency makes the members feel that they have a common fate, thus building strong identification with the group (Rabbie \& Horwitz, 1988; Rabbie, Schot, \& Visser, 1989). Based on the above discussion, we made the second prediction. When participants in the present study observed that a victim was harmed, they were likely to respond aggressively to the harm-doer if they were engaging in a cooperative group work with the victim than if they were not (Hypothesis 2).

\section{METHOD}

\section{Participants and Experimental Conditions:}

96 students of a large public university in Japan (49 men and 47 women) were recruited from a psychology class to participate in the experiment. They were given a 500-yen book coupon as reward. They were randomly assigned into four conditions (each $N=24$ ): 2 (high or low similarity) $\times 2$ (cooperative experience or non-cooperative experience).

\section{Procedures:}

Before starting the experiment, the participants were asked them to engage in two tasks and answer a questionnaire. One task was a picture completion test and the other was to make a title for a short piece of writing. The purpose of the tasks was explained as to assess personal skills, and the questionnaire was to assess traits of the participants. Experimenter explained the result of these tasks would be used experiment. When participants arrived at the laboratory, there were two other participants (one of them was the confederate, but she was introduced as participant). The experimenter explained that this experiment consisted of two sessions. The first session was to measure creativity, and the second session was to examine effects of stress on creativity. The experimenter told the participants that there was another group of participants in a different room, and they would communicate with the group in the second session. The experimenter further explained that a group of professionals would evaluate the level of creativity of both groups.

Similarity. The experimenter said to the participants (and the confederate) in the high similarity condition, "This group consists of members who have something in common (what they had in common was left unclear). In the low similarity condition, the experimenter told, "This group consists of members who are randomly assigned."

Cooperative experience. After that, the participants were engaged in the creative puzzle task. This task was to produce figures (animal, building, and vehicle) by assembling geometric blocks as soon as possible. In the cooperative experience condition, the participants were asked to complete the task in collaboration with other participants (and the confederate). It was impossible for them to finish the task unless they cooperated with other members since the blocks necessary to complete the figures were divided between the members. In the non-cooperative experience condition, the participants were asked to complete the task by themselves. In both conditions, the confederate was asked to pretend to cooperate with participant moderately. Explaining that the professionals in a different room would evaluate creativity of these products, the experimenter brought them out of the laboratory.

Stress session. In the second session, the experimenter explained that the second creativity task was a picture completion test, in which a participant would be asked to draw five pictures, such as objects or landscapes, including given simple shapes (e.g., "Y"). Emphasizing that the purpose of this session was to examine the effect of stress on creativity, the experimenter further explained that the two participant groups would exchange the pictures to evaluate each other. Then, the experimenter asked the confederate to draw pictures. The confederate pretended to draw pictures for the first time, but she drew identical ones in every time. The participants were asked to observe that the confederate drew pictures. And the experimenter explained that these pictures would be evaluated by the other group. The two participants in each condition 


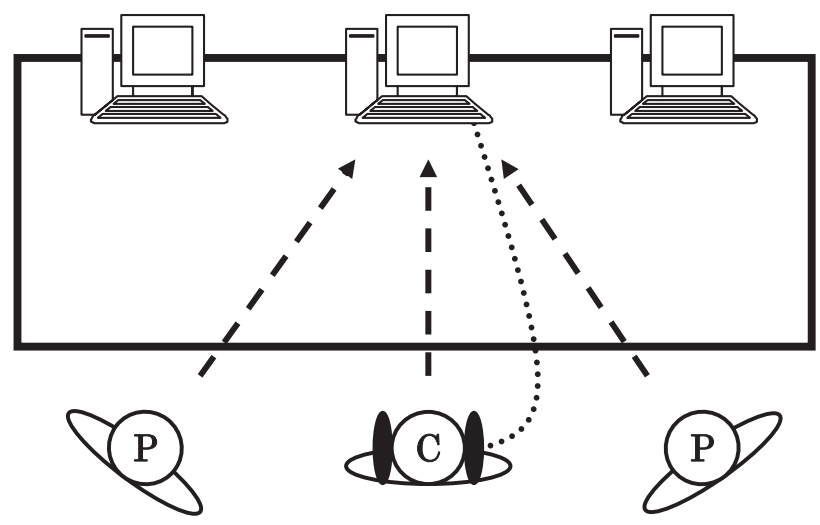

\section{P: Participant \\ C: Confederate}

Fig. 1. Observation of the victim being harmed. Two participants were asked to observe that the confederate received evaluation.

were asked to evaluate pictures made by a member of the other group. In the evaluation, the experimenter stressed that originality or uniqueness should be given more weight than elaborateness.

Observation of the victim being harmed. After the confederate completed the five pictures, the experimenter carried and exchanged them with the other group in a different room. Then, the participants observed the confederate being harmed by the other group in the evaluation of the pictures. For the evaluation, a personal computer was used. On its display, there were 9 evaluation buttons labeled " 1 (Extremely creative)" through "9 (Not creative at all)." The experimenter explained that these evaluation buttons were connected to different levels of discomfort noises; that is, the poorer evaluation the evaluator made, the louder noise the writer would receive. The volume levels of noises were $40 \mathrm{~dB}$ (Level 1) through $80 \mathrm{~dB}$ (Level 9), increasing $5 \mathrm{~dB}$ across levels. As samples, the participants were given the 3, 5, 7, and 9 level through a headphone.

Fig. 1. shows a layout of the laboratory. The confederate who had drawn the pictures sat in the middle of the table wearing a headphone. A computer display was put on the table, so the participants could see which levels of evaluations and noises the confederate received. In every condition, the participants observed that the confederate received five poor evaluations (loud noises at the levels of "7", "9", "7", "8" and "9"). During the confederate was given noises, she did not talk with participants.

Measurement of aggression. The experimenter then gave each participant five pictures that were drawn by a member of the other group and asked him/her to evaluate them using the personal computer. The experimenter instructed participants to click one of the nine evaluation buttons for each picture, and explained that the member of the other group would continue to hear the noise for six seconds. The measurement of aggression consisted of the noise intensity that each participant chose for each picture. In the measurement, partitions were placed between the participants and confederates so that they could not see each other (Fig. 2.).

Measurement of the mediating variables. After the evaluation task, each participant was asked to answer a series of questions using the personal computer. One question to measure the perception of threat was "When you observed the person next to you receiving noises from the other group, how strongly did you judge the harm-doers' hostility to be?" Another question to measure the level of hostility against the harmdoer was "When you observed the person next to you receiving noises, did you have feelings of hostility 


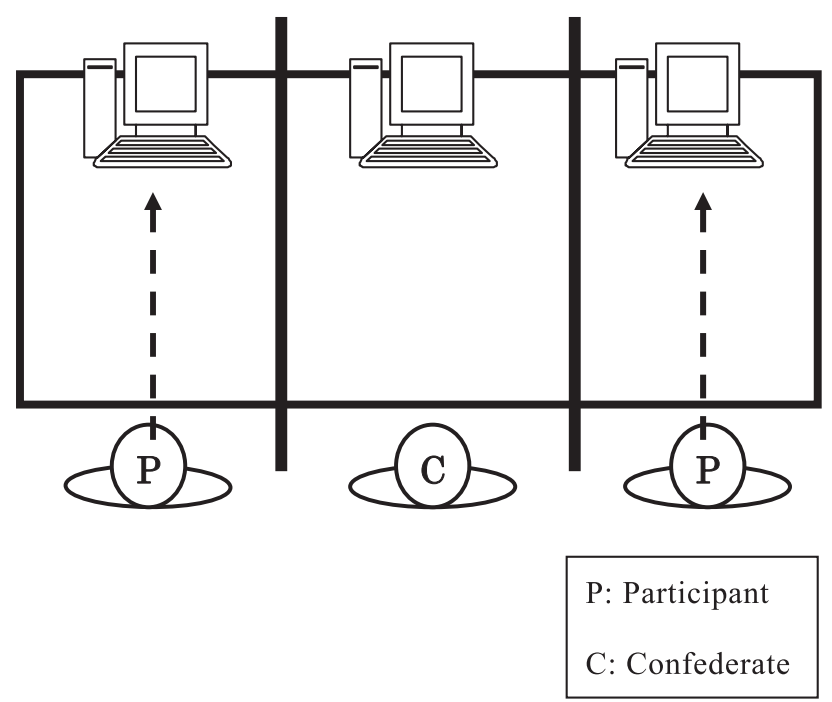

Fig. 2. Measurement of aggression. Partitions were placed between the participants and confederate so that they could not see each other's evaluation.

toward the harm-doer?" Finally, one question to measure aggressive intent was "When you gave noises to a member of the other group, how strong were your intentions to cause the person pain?" For each of these questions, the participants made a rating on a 7-point scale ranging from 1 (Not at all) to 7 (Definitely).

Debriefing. After the experiment, the experimenter debriefed each participant of the true purpose of the experiment, hypotheses, experimental design, and procedures. In the explanation, the experimenter explained that there were neither professionals nor other participant groups. The participants were assured that they did not harm anyone.

\section{RESULTS}

\section{Aggressive Behavior}

We used the intensity of noises that participant gave to other group member as the measure of aggression. We examined the intensity of noise by a three-way ANOVA with a design of similarity $(2) \times$ cooperative experience $(2) \times$ picture $(5)$. Similarity and cooperative experience were between-participant effects and picture was a withinparticipant effect. A main effect of the picture was highly significant, $F(4,368)=38.98$, $p<.01$. The mean scores of pictures were 4.6, 5.5, 5.1, 7.0, and 6.4, showing that the participants gave more intense noises to the fourth and fifth pictures than to the first three pictures $(p s<.01)$. Interaction between similarity and picture was significant, $F(4$, $368)=2.77, p<.05$. Multiple comparison indicated that on the fifth picture the participants in the high similarity condition $(M=4.7,5.4,5.4,7.2,7.3)$ selected more intense noise than those in the low similarity condition $(M=4.4,5.5,4.8,6.6,6.0)$. 


\section{Mediating Variables}

We examined the ratings of perception of threat, hostility, and aggressive intent by two-way ANOVA with a design of similarity (2) $\times$ cooperative experience (2). Differences between the cooperative and the non-cooperative conditions were significant in the perception of threat, $F(1,92)=5.90, p<.05$, hostility, $F(1,92)=11.56, p<.01$, and aggressive intent, $F(1,92)=12.11, p<.01$. The participants who experienced cooperation perceived threat more strongly $(M=3.7)$ than those who did not $(M=2.9)$. The participants who experienced cooperation felt more hostility against harm-doer $(M=3.9)$ than those who did not $(M=2.9)$. Moreover, the participants who experienced cooperation had aggressive intent more definitely $(M=3.5)$ than those who did not $(M=2.4)$.

\section{Path Analysis}

To examine the effects of experimental factors and mediational effects of perception of threat and aggressive intent on aggressive reactions, we conducted a path analysis using the structured equation modeling (SEM). As a measure of aggressive reaction, we used the mean score of picture 4 and 5. Mean evaluation scores of pictures 1 through 3 were around the middle point, suggesting that the participants refrained from negative evaluation at these first occasions. Contrary, the mean scores of pictures 4 and 5 were above 6 , suggesting that the participants became freer to express their evaluation at these last occasions. This evaluation pattern indicates that the evaluation of pictures 4 and 5 is a more valid index of aggression.

We made a theoretical model: First, the two experimental factors generated the perception of threat; then, the perception of threat increased aggressive intent, which in turn prompted the aggressive reaction. We analyzed this model by using AMOS (Arbuckle, 1999, Version 4.0). The model had good fitness to the data, $\chi^{2}$ $(\mathrm{df}=6)=12.79, p=.05, \mathrm{GFI}=.95, \mathrm{AGFI}=.88, \mathrm{CFI}=.86$, with all the paths being significant except that from the similarity to the perception of threat (Fig. 3). To improve the fitness, we deleted the nonsignificant path and added direct paths from the similarity to the aggressive reaction and from cooperative experience to aggressive intent. The resultant diagram (Fig. 4) showed much better fitness, $\chi^{2}(\mathrm{df}=5)=1.77, p=.88$, $\mathrm{GFI}=.99, \mathrm{AGFI}=.98, \mathrm{CFI}=1.00$. Consistent with our predictions, it was shown that cooperative experience generated the perception of threat, and it increased aggressive intent, which in turn prompted aggressive reaction. However, there were some unexpected effects: The cooperative experience directly increased the aggressive intent and the similarity directly prompted the aggressive reaction.

\section{DISCUSSION}

In this study, we experimentally examined whether or not people aggressively get involved in conflicts. Specifically, we tested the hypothesis that this type of aggression would be enhanced by group identification. Consistent with the hypothesis, it was found 


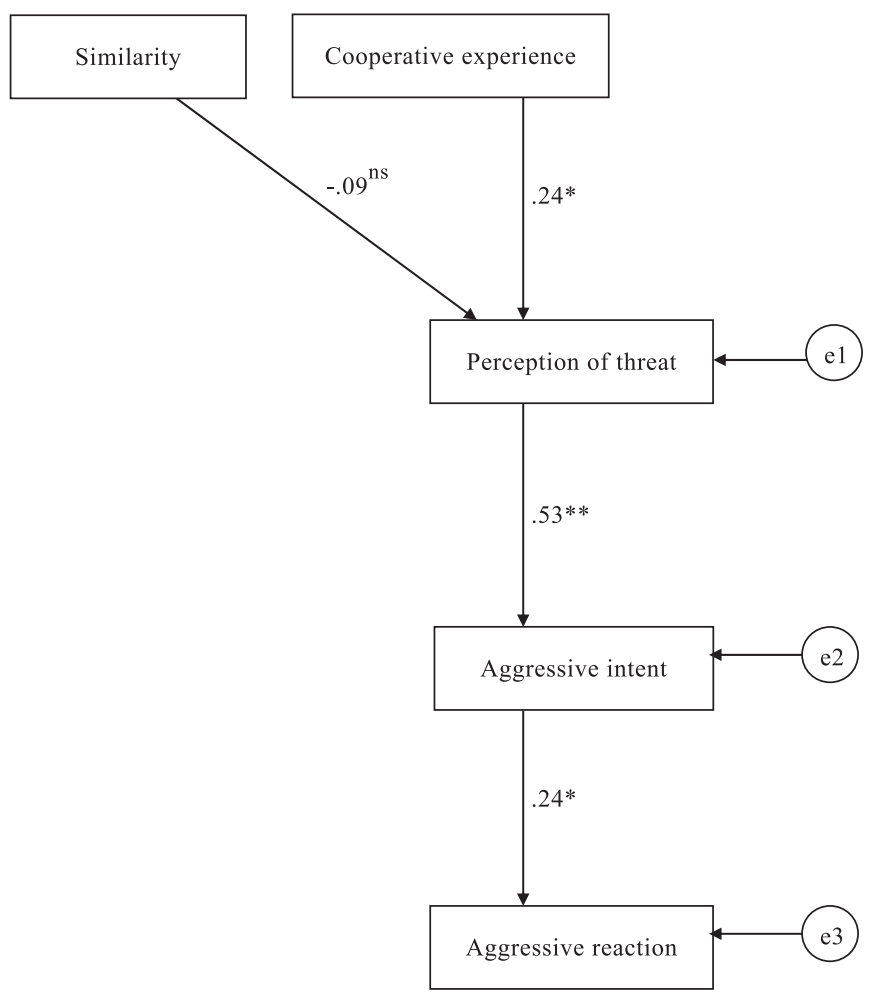

Fig. 3. Theoretical path model: the two experimental factors generated the perception of threat, then the perception increased aggressive intent, which in turn prompted the aggressive reaction. ${ }^{\text {ns }} p>.05$. $* p<.05 . * * p<.01$.

that the participants who shared the similarity and interdependency with the victim showed more aggressive behavior toward the harm-doer than those who did not.

Further, we made two hypotheses regarding the social psychological process of the third party aggression. Hypothesis 2 predicting that the cooperative experience would enhance the sense of group identification was supported. Although the cooperative experience did not directly affect aggressive behavior, SEM (Fig. 4) showed that the perception of threat and aggressive intent mediated between them, suggesting the presence of social psychological processes we assumed. That is, the cooperative experience induced identification with the group, so the participants felt as if they were being harmed (perception of threat) and aggressed the harm-doer with a hostile intention like a victim. SEM indicated that, not only by way of the perception of threat, the cooperative experience also directly enhanced aggressive intent. The participants might have had some negative emotions, such as anger or resentment, and negative cognitions, such as injustice, but the measure of threat might not be adequate to assess these negative psychological variables. In the future research, we should add more measures for them.

SEM further suggests that the similarity differently influenced aggressive reactions 


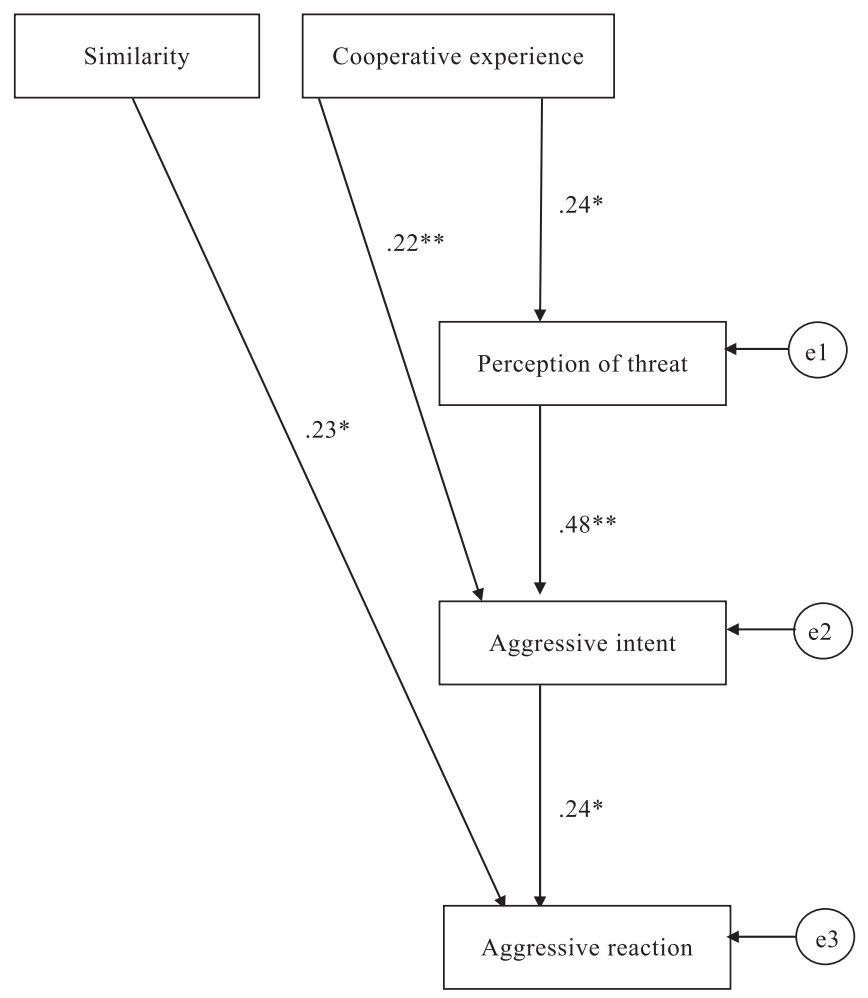

Fig. 4. Modified path model: To improve the fitness, the nonsignificant paths were deleted and direct paths were added from the two experimental factors to the aggressive intent and aggressive reaction. ns $p>.05 . * p<.05$. ** $p<.01$.

to the observation of harmed ingroup member. We predicted in Hypothesis 1 that participants who shared similarity with victims would become more sensitive to threat and to react more aggressively than those who did not. This was only partly supported. As Fig. 4 showed, the participants who were implied of their similarity selected stronger noises than those who were not, but that the similarity directly intensified aggressive reactions to the outgroup member without mediation by the group process variables (the perception of threat and the aggressive intent). We interpret that the participants perceiving similarity with the victim might have responded personally to harm, but not as a group member. We expected that intragrouop similarity enhanced group identification, but it might be possible that the similarity enhanced personal concern for the other person, not as an ingroup member. This remains just a possibility because the level of group identification was not measured in the present study.

In the present study, we examined in a laboratory setting aggressive intervention by the third party who did not personally suffer. Although the results were not perfectly consistent with our hypotheses, they suggest the social psychological processes involving group identification and inter-group retaliation. The perception that the status of ingroup 
was threatened prompted retaliation against an outgroup, providing a clue for the understanding why inter-group conflicts are so often escalated by third party intervention. When third party persons observed that ingroup member was harmed, they recognized it not only as a harm to other person, but also as harm to the ingroup and so to themselves. Thus third party spontaneously aggressed to harm-doer. This is the reason why people who do not suffer any damage sometimes intervene with conflict, making it worse. Since the end of the Cold War when pervasive ideologies declined, inter-ethnic conflicts have occurred in many areas of the world and escalated to shake countries in some cases. Journalists have pointed out that they are often escalated by people's spontaneous participation in the conflicts, and their participation is prompted by group identities, like nationalism or ethnocentrism (e.g., Volkan, 1997). What we found in the present study is consistent with these views. In future research, we must examine how other types of group identification enhance third party aggression and inter-group conflict in detail.

\section{REFERENCES}

Arbuckle, J. L. 1999. Amos (Computer Software). Chicago: Small waters Corp.

Baron, R. A., \& Richardson, D. R. 1994. Human aggression. New York, NY: Plenum Press.

Brewer, M. B., \& Kramer, R. M. 1986. Choice behavior in social dilemmas: Effects of social identity, group size, and decision framing. Journal of Personality and Social Psychology, 50, 543-549.

Brewer, M. B., \& Pickett, C. 1999. Distinctiveness motive as a source of the social self. In T. R. Tyler, R. M. Kremer \& O. P. John (Eds.), The Psychology of the Social Self. Hillsdale, NJ: Erlbaum.

Dengerink, H. A., \& Covey, M. K. 1983. Implications of an escape-avoidance theory of aggressive responses to attack. In R. G. Geen, \& E. I. Donnerstein (Eds.), Aggression: Theoritical and empirical reviews. New York, NY: Academic Press.

Ellemers, N., Doosje, B. J., Van Knippenberg, A., \& Wilke, H. 1992. Status protection in high status minority groups. European Journal of Social Psychology, 22, 123-140.

Ellemers, N., Van Rijswijk, W., Roefs, M., \& Simons, C. 1997. Bias in intergrouo perceptions: balancing group identity with social reality. Personality and Social Psychology Bulletin, 23, 186-198.

Huntington, S. P. 1996. The clash of civilizations and the remaking of world order. New York, NY: Touchstone Books.

Ignatief, M. 1998. The warrior's honor: ethnic war and the modern conscience. Ontario, Canada: Owl Books.

Jackson, J. W., \& Smith, E. R. 1999. Conceptualizing social identity: A new framework and evidence for the impact of different dimensions. Personality and Social Psychology Bulletin, 25, 120-135.

Mackie, D. M., Devos, T., \& Smith, E. R. 2000. Intergroup Emotions: Explaining offensive action tendencies in an intergroup context. Journal of Personality and Social Psychology, 79, 602-616.

Ohbuchi, K. 1996. Motivational perspectives of aggression and the two-process model. Tohoku Psychologica Folia, 55, 80-91.

Postmes, T., Spears, R., Sakhel, K., \& de Groot, D. 2001. Social influence in computer-mediated communication: the effects of anonymity on group behavior. Personality and Social Psychology Bulletin, 27, 1243-1254.

Rabbie, J. M., \& Horwitz, M. 1969. Arausal of ingroup-outgroup bias by a chance win or loss. Journal of Personality and Social Psychology, 13, 269-277.

Rabbie J. M., \& Horwitz, M. 1988. Categories versus group as explanatory concepts in intergroup relations. European Journal of Social Psychology, 18, 117-123.

Rabbie, J. M., Schot, J. C., \& Visser, L. 1989. Social identity theory: A conceptual and empirical critique from the perspective of a behavioural interaction model. European Journal of Social Psychology, 19, 171-202. 
Rosenbaum, M. E., Moore, D. L., Cotton, J. L., Cook, M. S., Hieser, R. A., Shover, M. N., \& Gray, M. J. 1980. Group productivity and process: pure and mixed reward structures and task interdependence. Journal of Personality and Social Psychology, 39, 626-642.

Tedeschi, J. T., \& Felson, R. B. 1994. Violence, aggression \& coercive actions. Washington, DC: American Psychological Association.

Tyler, T. R., Degoey, P., \& Smith, H. 1996. Understanding why the justice of group procedures matters: A test of the psychological dynamics of the group-value model. Journal of Personality and Social Psychology, 70, 913-930.

Volkan, V. 1997. Bloodlines from ethnic pride to ethnic terrorism. New York, NY: Farrar, Straus and Giroux.

(Manuscript received March 18, 2005; Revision accepted December 16, 2005) 